\title{
Livro Didático Adaptado em Libras: Espelho da Cultura Educacional
}

Dayse Garcia MIRANDA*

* Doutora em Estudos de Linguagens do CEFET/MG, 2019. Professora adjunta do Departamento de Letras da UFOP/MG. Contato: dayse.miranda@ufop.edu.br

\section{Resumo:}

Este artigo se propõe a tratar especificamente do livro didático (LD) adaptado em língua de sinais (LS) pensando esse suporte pedagógico como espelho da cultura escolar. A discussão apoiará em pesquisadores — Basso (2003), Souza (2015), Moses, Golos e Holcomb (2018), Krusser (2017), Munakata (2016), Ramos (2013), Miranda (2010, 2019) e Silva et al. (2013) - que discutem sobre materiais didáticos específicos para crianças surdas. Dessa forma, intenciona uma revisão da literatura pertinente ao tema. Apresentar uma reflexão sobre a relação da escola com os materiais didáticos adaptados em Libras, à entrada das Tecnologias de Informação e Comunicação (TICs) no ambiente escolar, a como os alunos leem esse texto sinalizado e a como as adaptações em língua de sinais podem construir sentidos a partir desse novo formato de leitura. Por fim, apontar as conjecturas descritas por estudiosos da área quanto a esses materiais didáticos.

\section{Palavras-chave:}

Libras; livro didático; surdez.

\footnotetext{
${ }^{1}$ Recorte da pesquisa de doutoramento de MIRANDA, D.G A multimodalidade no ensino da língua portuguesa como segunda língua para surdos: Análise do uso do livro didático adaptado em libras. POSLING-CEFET/MG. 2019.
} 


\section{Livro Didático Adaptado em Libras: Espelho da Cultura Educacional}

Dayse Garcia Miranda

\section{INTRODUÇÃo}

O livro didático (LD) é mais que um simples objeto dentro do ambiente escolar. Ocupa um lugar significativo e é um instrumento didático-pedagógico fundamental no processo de escolarização. Normalmente, o LD é um material impresso elaborado por especialistas de diferentes áreas, composto por textos, sistematizações, exemplos e exercícios que auxiliam o professor na dinâmica da sala de aula. Com o avanço da tecnologia, no campo da educação, o LD tem sido enriquecido por componentes midiáticos. Atualmente, encontra-se em versões digitalizadas, que podem ser uma simples digitalização da página impressa como a inclusão de animações, site indicando links e/ou com um CD-ROM.

Considerando o LD a partir das primícias sociais da língua(gem), temos, em Prediger e Kersch (2013), a informação de que o livro didático, no século passado, era composto por palavras, orações e linhas em cores pretas e/ou azuis, com fundo branco e algumas imagens em preto e branco. A "linguagem predominante era a escrita, acompanhada da linguagem visual, que ilustrava ou auxiliava o texto escrito” (PREDIGER; KERSCH, 2013, p. 211). Bastava compreender a gramática da língua escrita para compreender o texto.

Analisando pelo princípio da Multimodalidade, orientando-se por Kress (2010, p. 1), o LD pode ser apontado como um meio de comunicação humana, que explora as formas de significação e inclui todos os modos semióticos envolvidos no processo de representação e comunicação. Nesta perspectiva, a escrita, os sinais, a imagem e a cor se prestam a diferentes tipos de trabalhos semióticos, cada um com potenciais distintos para a representação. Para o autor, a razão para isso está nas redes de mudanças sociais, econômicas e culturais, entrelaçadas pela tecnologia. A significação não é globalizada, está em consonância com os efeitos das mudanças sociais. Dessa maneira, defende-se a ideia de que a representação do LD está moldada pelas práticas sociais de uso desses modos discursivos, e assume uma forma particular de significação como resultado das interações específicas de um determinado grupo social.

Geralmente, o LD carrega a definição de ser qualquer livro, em qualquer suporte — impresso em papel, gravado em mídia eletrônica etc. —, produzido explicitamente para ser utilizado na escola, com fins didáticos. Munakata (2016, p. 121) defende um conceito mais fluido afirmando que sua função está diretamente relacionada ao lugar que o LD ocupa na cultura escolar.

Para entender o que se nomeia de "cultura escolar", temos, em Durkheim (1968), citado por Munakata (2016, p. 121), a afirmação que a "educação consiste num esforço contínuo para impor às crianças maneiras de ver, de sentir e de agir às quais elas não chegariam espontaneamente". A escola está diretamente associada à realidade social. Assim, a escola, vista da sociedade, pode aparecer como um minúsculo ponto, inteiramente marcada pelas determinações da esfera macrossocial. Nessa conjectura escolar, privilegiam-se não tanto os aspectos normativos da escola, mas a multiplicidade e a criatividade das experiências cotidianas dos participantes desse espaço educativo. 
O importante é, então, levar em conta que a noção de cultura escolar refere-se não apenas a normas e regras, explícitas ou não, símbolos e representações, além dos saberes prescritos, mas também, e sobretudo, a práticas, apropriações, atribuições de novos significados, resistências, o que produz configurações múltiplas e variadas, que ocorrem topicamente na escola. Afinal, não há como negar que haja coisas que só existem na escola. Não por acaso, a noção de cultura tende a aplicar-se a identidades peculiares, a comunidades delimitadas - cultura negra, cultura indígena, cultura gay — e, por que não? - cultura escolar (MUNAKATA, 2016, p. 122).

Ao discutir o manejo do LD adaptado em LS pelo aluno surdo, deve-se considerar a Escola parte do objeto de estudo, principalmente quando o objeto investigado traz à luz as propostas educacionais para o atendimento do surdo. Mesmo sendo, a reflexão quanto ao LD adaptado e o aluno surdo, as características do professor e da escola estarão refletidas na ação do aluno. Como também é importante ter em mente que o LD é um objeto dotado de materialidade, mesmo quando seu suporte é digital. Sendo o LD um objeto material (digital ou não), apresenta uma visualidade que precisa ser decodificada de acordo com sua modalidade representativa. Em outras palavras, o uso do LD em papel e tinta estabelece uma relação de uso diferenciada da do uso por meio de um CD.

Para Munakata (2016, p. 133), o livro didático fornece indícios para examinar a escola como local de experiência estética e considera polêmica a relação entre a cultura escolar e a sociedade inclusiva. De fato, pode-se inferir que a entrada de alunos com necessidades educativas diferenciadas interfere na dinâmica escolar e demanda um novo paradigma da escola e do uso de recursos com fins pedagógicos. Nesse caso, pode o LD adaptado em Libras fornecer indícios de a escola estar adequadamente preparada para o uso dessa modalidade visual? Isto é, as diretrizes propostas pela Escola caminham de mãos dadas com as transformações arquitetônicas ${ }^{2}$, tecnológicas ${ }^{3}$, ideológicas ${ }^{4}$, entre outras, para efetivar a inclusão de um específico estudante?

Ao considerar o material didático um instrumento para criar condições de ensino e aprendizagem, no caso da surdez, do LD adaptado em Libras, nota-se que as duas modalidades de língua (LS e língua portuguesa [LP]) circulam no produto e se constituem com fins didáticos. Contudo, cabem questionamentos: a LP se constitui legalmente nessa ferramenta como segunda língua? O LD adaptado em Libras é um recurso pedagógico apropriado para a criança surda? No decorrer do artigo, algumas dessas indagações podem ser respondidas.

\section{Adaptação de Livros Didáticos: TiCs Acessibilidades Para o Aluno Surdo}

Ao se tratar de LD adaptado em LS, pressupõe-se a tradução do texto escrito para o texto sinalizado, isto é, tradução da Língua Portuguesa escrita para a Língua de Sinais registrada em vídeo. Dessa forma, a tradução é encarada através de um enfoque não apenas linguístico, mas intercultural.

Ressalta-se a importância de compreendermos a ideia difundida por Bakhtin (2002) citada por Miranda (2010, p. 67) quanto à enunciação, pois ela dará subsídios à compreensão dos aspectos que

\footnotetext{
${ }^{2}$ Espaço físico da escola.

${ }^{3}$ Tecnologia: ferramenta a favor do ensino. O termo tecnologia educacional remete ao emprego de recursos tecnológicos como ferramenta para aprimorar o ensino. É usar a tecnologia a favor da educação, promovendo mais desenvolvimento socioeducativo e melhor acesso à informação. Disponível em: https://www.portaleducacao.com.br/conteudo/artigos/direito/tecnologia-educacional-uma-ferramenta-afavor-do-ensino. Acesso em 5 de nov. 2018.

${ }^{4}$ Apoia-se em Pimenta (2001) para conceituar a ideologia como um conjunto de versões do mundo imposta por um grupo social em outro grupo em nomes de interesses próprios ou distintos. Assim, produz um mecanismo de controle de um grupo dominante presente em atos semióticos.
} 
envolvam a competência tradutória e o público para o qual se traduz. A enunciação é vista como um modelo de diálogo social que tem como base a língua, e o seu uso reflete o contexto social de onde e para quem é produzida. Dessa maneira, a noção da enunciação está focada, portanto, na ideia de que ela é constituída no ambiente sócio-histórico, acabada, e que se perpetua em uma dimensão discursiva implicada no processo das relações interativas dos participantes.

Essas ideias se alinhavam com os estudos da multimodalidade e define-se que a comunicação é um processo no qual um "produto" 5 é, ao mesmo tempo, articulado e interpretado. Os autores envolvidos — escritores, editores, intérpretes de Libras, professores e alunos surdos — dependem de uma relação comunicativa interpretativa, ou seja, que o interpretante final (surdo/a) tenha conhecimento da língua de sinais e do assunto para entender a mensagem. "A comunicação não acontece somente no polo do produtor, mas depende também do interpretante; assim, podemos entender que a estrutura e os processos sociais estão inevitavelmente presentes na comunicação" (NATIVIDADE; PIMENTA, 2009, p. 24).

Nesse sentido, faz-se necessário ponderar quanto a tradução desses materiais. $\mathrm{Na}$ educação temos ações que envolvem comunicação, troca de conhecimentos, interações discursivas - orais/escritas/ sinalizadas. Ações que implicam em um esforço que visam conferir ao indivíduo as disposições linguísticas para alcançar entendimento. Entende-se que a língua é um mecanismo usado como recurso de ensino. No entanto, a língua, por si só, não pode garantir o processo educativo. Como consequência, não se pode garantir que a tradução dos recursos didáticos seja suficiente para ofertar a condição de isonomia dos alunos surdos aos alunos ouvintes.

A partir da perspectiva de propor reflexão do LD adaptado em Libras, é relevante dar atenção às tecnologias de informação e comunicação, uma vez que a adaptação só acontece apoiada nesses recursos computacionais.

A tecnologia possibilita a combinação de várias linguagens em um mesmo material, e sua escolha ocorre de acordo com o propósito comunicativo, sendo feita pelos produtores de mensagens visando ao público-alvo. O público-alvo, por sua vez, é o fator que motiva, guia e dá sentido a qualquer escolha de composição do texto multimodal. Recapitula-se, daí, a defesa do LD como esse gênero de unidades discursivas significativas.

Ao mesmo tempo em que a comunidade surda ganha maior força em suas reivindicações por direito e justiça social, a ciência avança em novas descobertas tecnológicas. A partir dessa visão, Basso (2003, p. 119) afirma que o avanço da tecnologia permitiu o surgimento de novos instrumentos de comunicação, principalmente a partir da internet, embora observa-se que a preservação da língua de sinais, identidade e cultura se mantém dentro da comunidade surda.

Essas novas possibilidades tecnológicas não alteram apenas a vida cotidiana das pessoas, mas alteram todas as ações, condições de pensamento e de representação da realidade. Para Freire (2003, p. 195), a integração de diferentes recursos verbais e não-verbais, característica da maior parte dos programas de multimídia, possibilita analisar o funcionamento discursivo da linguagem de uma maneira peculiar. A autora afirma que, a partir da concepção da surdez como uma experiência visual, ponderando todos os aparatos relacionados à surdez (linguístico, cultural, intelectual e outros), a inserção das TICs na educação de surdos pode construir um espaço privilegiado de produções narrativas e de entrada do aluno surdo no mundo letrado.

No artigo "Creating and Using Educational Media with a Cultural Perspective of Deaf People" (MOSES; GOLOS; HOLCOMB (2018, p. 68-71), argumentam que a mídia educacional para crianças surdas tem o potencial de apresentar a LS com precisão e uso. Quando as crianças surdas não veem a LS em casa nem na escola, literatura ou mídia, sentem-se inferiorizadas e envergonhadas e se levam a se questionar quem são. Algo tão simples, como promover a representatividade das crianças surdas a partir de personagens

\footnotetext{
${ }^{5} \mathrm{~A}$ tradução para a língua de sinais dos LD's.
} 
surdos na mídia, pode afirmar e validar a própria existência desses sujeitos e impulsionar sua motivação e aprendizado. A mídia educacional pode funcionar como espelho para a formação da identidade de crianças surdas ou como ganhos quanto ao aprendizado da primeira e segunda língua; pois, fornece modelos de uso da LS. Segundo as autoras, crianças surdas em contato com a LS, a partir das TICs, apresentam maior consciência fonológica da LS e, por sua vez, conquistam maior compreensão fonológica da língua oral (LO). Por fim, defendem que a tecnologia de comunicação deve incorporar o modelo linguístico e cultural das pessoas surdas, bem como assegurar ambientes midiáticos culturalmente apropriados que promovam interações na LS.

Dessa forma, sob esses desafios, integrar TICs e materiais impressos ao processo educacional dos surdos como ferramenta pedagógica não pode ser visto como um simples instrumento tecnológico, mas como condição de proporcionar acesso pelo usuário e, por assim, torná-lo um indivíduo crítico e autônomo, que descobre e cria suas próprias respostas mediante essa ferramenta. Para Basso (2003, p. 121), significa compreender novos códigos de leitura e escrita, novas linguagens e novas formas de interpretar o acesso ao ensino e aprendizagem e seu lugar na educação. A possibilidade de dispor de recursos visuais facilita a inserção das pessoas surdas e favorece esses usuários. Em particular, a partir dessa concepção, pode-se supor que as tecnologias possibilitam uma nova visão textual, isto é, aspectos multimodais representam diferentes modos discursivos.

Vale destacar, quanto à experiência na adaptação de LDs para alunos surdos, o relato de Célia Ramos, diretora-executiva da editora Arara Azul, responsável pela adaptação em Libras de duas coletâneas para as séries iniciais do ensino fundamental — Coleção Pitanguá, pela editora Moderna, e Porta Aberta, da FTD Educação:

Sempre acreditamos que o material que produzimos fosse apenas mais uma ferramenta, considerando que o Livro Digital ${ }^{6}$ fosse apenas e simplesmente um Livro em uma mídia diferente. Porém, nos enganamos. É necessário repensar todo o histórico da educação de surdos, as questões específicas da cultura surda e, também, o relacionamento de surdos e ouvintes com o mundo digital (RAMOS, 2013, p. 8).

A autora, em seu artigo sobre o trabalho de adaptação dos LDs, expõe vários argumentos apresentados por professores quanto à operacionalidade do livro digital e, com isso, foi necessário pensar na capacitação dos profissionais para a utilização desse LD. Muitos professores afirmaram que o CD-ROM não era bilíngue e que apenas reproduzia o livro em papel (LP escrita), pois não sabiam que poderiam acionar, por um clique, a janela do vídeo que reproduz o conteúdo em Libras. Segundo Ramos (2013), alguns professores não acreditavam que seus alunos surdos pudessem acessar os mesmos conteúdos que os ouvintes, e outros solicitaram curso de Libras para maior interação com o aluno.

Ramos (2013) aponta que a maioria das escolas não tem disponibilidade para oferecer um computador a cada aluno surdo, o que dificulta o uso do material em classe inclusiva. Outro fator apresentado foi que, em algumas escolas, o aluno ouvinte não fazia uso da Coleção Pitanguá. A autora afirma que esses entraves podem ser solucionados com as políticas educacionais públicas destinadas à educação bilíngue. Entende que:

[...] essa ação abriu uma porta que nunca mais se fechará, já que a proposta do Livro Didático Digital Bilingue (Português e Libras) passou a ser uma realidade e não mais um sonho e sua utilização, avaliação adequação e ampliação, certamente, será uma questão de tempo (RAMOS, 2013, p. 8).

\footnotetext{
${ }^{6}$ Livro digital: termo identificado no artigo de Ramos (2013), entretanto não usual nos artigos que discutem sobre livro didático quanto elaboração e uso. Mantem o uso da expressão em respeito ao termo apresentado pela autora.
} 
Enfim, quanto às TICs, temos Freire (2003), que orienta para uma reflexão mais aprofundada sobre a acepção dos termos tecnologias adaptativas on assistivas, como "soluções de hardware e ou de software que objetivam eliminar barreiras que impedem o manuseio do computador” (2003, p. 195).

Entretanto, na reflexão de Lins (2012), conjectura-se que, muitas vezes, como se percebe, as questões não dizem respeito somente às adaptações dos elementos tecnológicos, mas linguísticos e discursivos.

[...] como é necessário no caso dos surdos usuários da LIBRAS (que não dominam o Português escrito com proficiência) ou no caso dos ouvintes, onde qualquer língua diferente daquela que esse usuário domina, impedirá que ele faça uso de todos os recursos tecnológicos ali disponíveis, ou seja, seria uma questão fundamentalmente de "tradução", onde os recursos para um hipertexto (na acepção trazida por GOMES (2010), ou software, por exemplo, podem ser (re)articulados, obviamente, a partir da compreensão das especificidades dos diferentes usuários e sua (s) língua(s). Diante disso, nesses casos, talvez o melhor termo fosse, então, tecnologias traduzidas (LINS, 2012, p. 3).

\section{Lendo Textos Sinalizados}

No ensejo de promover acessibilidade educativa para crianças surdas, a elaboração e a adaptação de materiais pedagógicos são as ações mais comuns. A entrada da LS nos materiais didáticos abre perspectivas de pensar outros aspectos que envolvem o ensino-aprendizado - para esse caso específico, ler em língua de sinais. Considerando a LS primeira língua (L1), língua visual representada pela imagem em movimento (vídeos/imagem) e base para que se chegue à língua oral escrita, podemos ponderar que a passagem de uma língua a outra só ocorrerá, nas premissas da surdez, através do olhar. Dessa forma, para adentrar no mundo da leitura de uma segunda língua (L2), deve-se percorrer, primeiramente, a leitura da L1. Assim, entende que crianças surdas leem em LS.

Para esse pressuposto, busco reflexões em Souza (2015), Krusser (2017) e Quevedo (2013), que investigaram as interações entre crianças/adultos surdos com TICs. Nesse sentido, temos pesquisas que dizem sobre recomendações para cursos on-line, com foco no público surdo, sintetizados na forma de um guia (SOUZA, 2015). Com maior ênfase, baseio nos estudos de Krusser (2017), que propôs identificar recursos gráficos e ferramentas computacionais que possam contribuir para uma leitura fluida e agradável, como também desenvolveu uma pesquisa aplicada com foco na tradução, de português para Libras, de textos com função didática e, por fim, em Quevedo (2013), em um estudo para composição de ambientes virtuais de ensino inclusivos voltados para estudantes surdos e ouvintes disponibilizando conteúdos similares em diferentes discursos narrativos. Embora as autoras enfatizem que exista pouca investigação no campo da pesquisa sobre a leitura em Libras, em se tratando de artigo que propõe refletir sobre o LD adaptado em Libras, não há como não perpassar, mesmo que sutilmente, por essa pauta.

A entrada da TICs na educação oportunizou novos produtos didáticos. Dessa forma, a escrita, comumente representada no modo impresso, passa para os ambientes da web configurada em diferentes modos discursivos. Entretanto, para Quevedo (2013, p. 32), as novas alternativas oferecidas pelas TICs requerem do ser humano um momento de adaptação, de desenvolvimento técnico para se adequar ao domínio e à potencialização dessas novas formas de leitura. A inserção da LS nos conteúdos audiovisuais educativos, a maioria a partir de vídeos, caracteriza-se por: (i) vídeo de língua oral/escrita, em que temos acessibilidade por legendas do texto oral em LP, tradução do texto (oral/escrito) em LS com intérprete humano ou intérpretes virtuais (avatares) e legendas (texto oral) em escrita de sinais (SOUZA, 2015, p. 95-100); (ii) vídeo em língua de sinais ${ }^{7}$ intercalado ao texto escrito (LS/LP), sendo a LS apenas para os

7 Modalidade de escrita disponível às pessoas surdas. 
enunciados de atividades escritas (BUSARELLO 2010, citado por QUEVEDO, 2013, p. 154); (iii) vídeo em língua de sinais, com tradução interlinguística ${ }^{8}$ e tradução do texto escrito para a língua de sinais (KRUSSER, 2017, p. 30); e (iv) vídeos sinalizados por surdos (MOSES et al., 2018, p. 67).

Saliento que, nesta investigação sobre LDs adaptados em Libras, a característica comum encontrada em todo o material foi uma tela digital em língua escrita e de acessibilidade feita por tradução do texto (escrito) em LS com intérpretes humanos.

Segundo os Parâmetros Curriculares Nacionais (2001), a leitura é um instrumento das práticas pedagógicas. Assim:

[...] é um processo no qual o leitor realiza um trabalho ativo de construção do significado do texto, a partir dos seus objetivos, do seu conhecimento sobre o assunto, sobre o autor, de tudo o que sabe sobre a língua: características do gênero, do portador, do sistema de escrita, etc. (PCN 2001, p. 53).

Ler é básico para o progresso na aprendizagem de qualquer assunto. A formação de um leitor competente, segundo os PCN (2001, p. 54), "só pode constituir-se mediante uma prática constante de leitura de textos de fato, a partir de um trabalho que deve se organizar em torno da diversidade de textos que circulam socialmente".

Nesse caso, Krusser (2017, p. 17) questiona se o leitor surdo se sente confortável ao estudar no material traduzido, se a leitura flui confortavelmente e se as interferências gráficas contribuem para os objetivos propostos pelo texto ou pelas diferentes partes do texto quando um texto escrito passa a ser apresentado em vídeo por um intérprete de LS. Ler vídeos em LS exige ações do leitor que são diferentes e bem menos estudadas até agora do que a leitura de textos escritos.

Ramos (2000), citada em Krusser (2017, p. 79), já adota o termo "leitor/espectador" e mostra que algumas características do vídeo sinalizado configuram o texto em Libras como uma "protoescrita". Com a tradução de um texto escrito para a língua de sinais, temos um vídeo que pode ser reproduzido, arquivado e visualizado em momentos diferentes sem necessitar da presença daquele que fala.

Ressalta-se que tipos distintos de texto promovem diferentes leituras. Diferentes modos discursivos demandam diferentes atitudes e envolvimento do leitor. Assim, Quevedo (2013) destaca que as diferenças ou similaridades de um conteúdo, a linguagem utilizada e seu modo de articulação configuram uma narratividade específica. Portanto, a possibilidade de apresentar um mesmo conteúdo instrucional em diferentes linguagens compõe discursos diferenciados (QUEVEDO, 2013, p. 15).

Ciente da complexidade envolvida no ato de ler nos diferentes tipos de textos e nas diversidades de recursos técnicos, para esta investigação, mantém-se a atenção nos aspectos que enfatizam as condições do leitor surdo para ler e compreender os vídeos em LS, recurso usual no que se refere à adaptação de LD em Libras. Muito relevantes são os aspectos apresentados por Krusser $(2017$, p. 81) quanto à eficácia, eficiência e satisfação do leitor surdo na leitura dos vídeos em Libras, por isso, os embasamentos para essa explanação serão orientados pela pesquisa dessa autora, que esclarece que não intenciona descrever aspectos que envolvam a leitura de textos escritos pelo surdo: o foco é na leitura de vídeos em LS.

Para Krusser (2017), dentro dos pressupostos da surdez, a aprendizagem e a compreensão do texto podem ser beneficiadas ou depender de uma abordagem mais visual. Assim, considera que a eficácia de um texto pode estar definida pela sua legibilidade, leiturabilidade e intencionalidade visual. Para a autora,

${ }^{8} \mathrm{O}$ processo de tradução da língua oral para LS se configura como uma tradução interlinguística (texto de partida e chegada estão em línguas diferentes). 
A legibilidade dos vídeos em Libras para uma leitura confortável depende principalmente das cores, relação figura e fundo, tamanho e resolução. A qualidade dos vídeos pode gerar arquivos de tamanho muito grande, que causam problemas para visualização em caso de conexões lentas com a internet, um tempo longo para download e espaço de memória considerável para arquivamento. A compactação dos vídeos pode ser feita na resolução espacial, com compactação das imagens de cada quadro, e na resolução temporal, diminuindo o número de quadros mostrados por segundo (KRUSSER, 2017, p. 88).

A autora destaca que a divergência entre os alunos surdos, na proficiência da língua de sinais entre os que estão no mesmo nível escolar, interfere na compreensão sobre as condições de leitura em textos sinalizados, embora um texto visível, com sinais reconhecíveis, não garanta sua compreensão nem que possa ser agradável e significativo9 (KRUSSER, 2017, p. 88).

Souza (2015, p. 81) aponta que, a partir de leituras de Marschark et al. (2009) e Quevedo, Busarello e Vanzin (2011), com relação à leitura de textos científicos escritos, o aprendizado dos surdos que conhecem LS foi melhor a partir do texto impresso (língua oral) do que por meio da língua de sinais. Isto é, os alunos surdos aprendiam mais a partir do texto impresso do que pela LS. Reforça a ideia de que não basta que o texto esteja legível para que o significado seja compreendido.

Continuando com os aspectos que envolvem a eficácia para a leitura, temos a leiturabilidade, característica que torna possível reconhecer o significado que auxilia na compreensão do texto.

No que se refere à leiturabilidade do material em Libras, o design pode planejar a interação do intérprete com as imagens e valorizar a organização dos elementos no espaço, que é uma característica da língua de sinais. Quando o intérprete descreve visualmente uma situação, pessoa ou objeto, ele indica sua posição no espaço e, quando volta a se referir à essa pessoa ou objeto, se direciona para o local em que o situou. Na configuração das páginas, podem-se explorar essas referências espaciais, movimentos, tamanhos relativos e elementos gráficos integrados com a interpretação para destacar informações e conduzir o olhar do receptor (KRUSSER, 2017, p. 90).

A autora Renata Krusser (2017, p. 93) aponta que os dicionários e glossários de LS oferecem opção para buscar as palavras do texto escrito; entretanto, os surdos encontram dificuldade na compreensão do sinal dentro da composição textual escrita, pois apresentam vocabulário limitado e muitos termos técnicos ainda não possuem sinais.

Segundo a autora, a ausência de prática com a leitura em sinais dificulta o reconhecimento das características estruturais do texto sinalizado, e, assim, pode proporcionar desentendimento na leitura. $\mathrm{O}$ último item, relacionado à eficácia do texto sinalizado, é a intencionalidade visual, promover o interesse do leitor pelo texto. Nesse campo, Krusser (2017) foca na vertente da tradução e, assim, considera pertinente refletir quanto a uma tradução que pretenda que o texto-meta cumpra a mesma função do texto de origem, escrito, levando em consideração os aspectos da cognição visual dos usuários da língua de sinais, o planejamento elaborado do design na tradução para Libras e a composição dos elementos que originam o texto sinalizado.

Na tradução de um texto escrito para um vídeo com texto em Libras ocorrerão necessárias transformações na forma. Tanto o texto escrito, como vídeo em língua de sinais apresentam conteúdos verbais, mas na tradução para Libras o texto escrito passa a ser apresentado por um intérprete em vídeo e o projeto editorial sofre uma mudança bastante radical exigindo um trabalho de (re)criação do design, utilizando outros elementos (KRUSSER, 2017, p. 106).

\footnotetext{
${ }^{9}$ Trata de características (design, vestimenta, estrutural frasal na Libras e outros) que tornam possível reconhecer o conteúdo, ou seja, contribuem para que se compreendam os significados do texto (KRUSSER, 2017).
} 
Depois da eficácia, Krusser (2017) considera importante analisar a eficiência da leitura. A eficiência pode ser medida pela agilidade da leitura, ou seja, a dedicação para alcançar o objetivo da leitura. O texto é facilmente compreendido, a leitura flui rápido e com naturalidade e proporciona melhor navegação e organização da leitura, fazendo com que o leitor atenda aos seus comandos.

O esforço despendido pelo leitor na percepção e compreensão do texto também é um aspecto que deve ser analisado no que se refere à eficiência na leitura. Consideramos que, se a carga de trabalho for muito elevada para completar o sentido do texto, o uso dos recursos visuais, propostos para o texto em Libras, pode ajudar a contextualizar e esclarecer os conceitos, além de contribuir, em alguns casos, para tornar a leitura mais ágil. Alguns conceitos, especialmente quando ainda não existem sinais para eles, podem necessitar de exemplos e explicações e exigir um tempo maior na apresentação em Libras do que o tempo para a leitura do texto escrito. Parece pertinente observar se o uso de imagens, vídeos, animações ou infográficos facilitaria a compreensão ou mesmo diminuiria o tempo de leitura (KRUSSER, 2017, p. 110).

Temos, em Coscarelli (1996, p. 449), a afirmação que a leitura é entendida como um complexo processo de fazer inferência, desde a percepção dos recursos imagéticos e gráficos, e acrescenta a ideia das composições estéticas de espaço tanto para texto em LP quanto para texto em LS. O leitor do texto midiático precisa entender seus significados para além do que está visualmente na tela. A produção de inferências é de extrema importância para a compreensão do texto. Segundo a autora, é o processo pelo qual o leitor (ouvinte/surdo) liga a informação textual a itens de seu conhecimento prévio e, assim, estabelece sua compreensão do texto.

Sobre a satisfação do leitor nos textos sinalizados, um fator relevante para esse quesito está no uso de uma identidade visual, voltada para crianças/adultos surdos (MOSES et al., 2018, p. 69), poder fazer com que esse leitor se sinta familiarizado com o material e experimente mais as opções da interface. É importante que ele se aproprie do material e se identifique com suas características. Isso pode também estimular a leitura. Aspectos como identificação com o intérprete de Libras e a sensação de omissão de informação podem interferir na satisfação do leitor surdo.

Os recursos de design utilizados para a leitura em língua de sinais podem envolver dois aspectos: um relacionado à interface onde será lido o texto, incluindo os elementos do player, que pode ou não oferecer ferramentas específicas para a leitura em LS, e outro, que são os elementos do design de cada texto traduzido. A interface deve contribuir para tornar claras a estrutura e a ordem do texto e oferecer as funcionalidades exigidas para diferentes objetivos do leitor, enquanto a tradução de cada material deverá contribuir para a fluidez e compreensão do texto (KRUSSER, 2017, p. 112).

A autora considera complexa a promoção de uma leitura agradável e significativa. Contudo, esses vídeos em LS devem seguir requisitos de qualidade para comunicação em LS na sua produção. Nos vídeos com textos em língua de sinais, a posição, o tamanho e a orientação da janela, bem como o uso de recortes ao fundo para sobrepor o intérprete em integração com outros elementos, interferem na leitura. Apesar das restrições, a comunicação por vídeo em LS é mais agradável e inteligível, sendo seu uso indicado por respeitar a comunicação natural dos surdos em sua L1. Por fim, para Krusser (2017, p. 214-215), as observações apontaram para a importância de se desenvolverem trabalhos de tradução específicos para o estudo em vídeos com textos em Libras envolvendo professores, tradutores e designers e considerando não apenas as diferenças linguísticas, mas as possibilidades didáticas e as contribuições do design para um estudo de qualidade na modalidade visual. 


\section{Materiais Didáticos de Ensino de Segunda Língua Para Surdos}

Adentrando nas questões que envolvem a surdez, muitos educadores têm a crença de que ausência de audição é responsável pelo baixo empenho na leitura e escrita de crianças surdas. A LS tem uma estrutura específica e não se assemelha à forma oral e/ou escrita da LP. O processo de aquisição do português escrito, por crianças surda, é complexo. As práticas de ensino de LP na educação de surdos se orientaram por uma concepção de língua como código, e assim resultou no ensino sistemático e padronizado de estruturas frasais da LP. Dessa forma, os alunos surdos aprendiam mecanicamente a LP sem compreensão da sua funcionalidade.

Quando a educação do surdo começa a ter um foco mais pedagógico, afastando-se da concepção de língua a partir da oralidade, a proposta de ensino de LP modifica sua configuração, e passa-se a apresentar características culturais e influência da LS como primeira língua nesses alunos. A pedagogia surda defende o aprendizado da LP como uma segunda língua, orientando-se para o ensino de uma linguagem mais usual e corriqueira, como também o uso da LS como mediadora de acesso ao conhecimento e como base para o aprendizado de LP. Assim, a língua de sinais é o fio condutor de todo o processo pedagógico (SILVA, 2008, p. 37).

Ao examinar as discussões sobre os materiais didáticos destinados aos alunos surdos, verifica-se ainda ser restrita a elaboração desse recurso pedagógico. Miranda (2019, p. 241), entrevistando professores bilíngues que lecionam para crianças surdas, observou que os próprios docentes produzem seus materiais de ensino orientando-se por imagens — retiradas de encartes, revistas e/ou de LD — e consideram que o mais importante é a inserção da LS.

Atenho aos LD e/ou MD de ensino da LP para surdos. Silva et al. (2013, p. 221) apontam dois livros utilizados para o ensino de português para esse público, com viés bilíngue: Meus primeiros sinais, do professor ouvinte Paulo Favalli (2000), e Brincando e aprendendo com Libras: lingua brasileira de sinais, desenvolvido pelas professoras surdas Irene M. Stock e Karin Lilian Strobel (1999), da Universidade Tuiuti do Paraná.

Os autores relatam que os livros ditos com viés bilíngue apresentam atividades que envolvem palavras e figuras soltas ou enunciados curtos, e por vezes desconectados, "que, muito provavelmente, apenas tem a intenção de auxiliar o ensino de conceitos concretos aos surdos" (SILVA et al., 2011, p. 7).

Barbosa e Bartholomeu (2016, p. 26) analisam a unidade 3 do livro Português... en quero ler e escrever, de Neiva Albres, publicado em 2010, e relatam que o interesse pela análise se deu por se tratar de um material que pode ser utilizado diretamente pelo aluno e que não se trata apenas de orientações ou atividades a serem adaptadas pelo professor. Explicam que a análise foi pelos aspectos gráfico-editoriais. Assim,

[...] verificamos que os aspectos gráficos estão bem dispostos nas páginas, o conteúdo é adequado ao público alvo, bem como foi possível constatar a realização de um trabalho com alguns elementos próprios da cultura surda. Contudo, observamos a necessidade de contextualização das atividades relativas aos aspectos lexicais e gramaticais, além de uma maior exploração das imagens que foram utilizadas. Conforme aponta Salles e colaboradores (2004), a língua de sinais é uma das maneiras dos surdos estarem no mundo e significá-lo. Eles apreendem o mundo com os olhos e, por isso, sua cultura está baseada na visão. Sendo assim, é importante que o livro didático voltado para o público surdo aproveite ao máximo os recursos visuais, para que o aluno com essa especificidade possa ter um aproveitamento melhor, no que tange ao aprendizado da LP (BARBOSA; BARTHOLOMEU, 2016, p. 26). 
As autoras terminam dizendo que os aspectos gráfico-editoriais presentes no material didático contribuem para o processo de ensino-aprendizagem de português como L2; entretanto, existe necessidade de produção de livros didáticos que contemplem as especificidades desse público de estudantes (BARBOSA e BARTHOLOMEU, 2016, p. 27). Em 2016, MORAIS e CRUZ (p. 108) apresentam artigo ${ }^{10}$ em que refletem sobre a elaboração de material didático para o ensino de LP como L2 para alunos surdos do curso de licenciatura em pedagogia bilíngue, modalidade EAD. As considerações finais sugerem que os materiais didáticos devam ser produzidos com conteúdo específico, que atenda às necessidades dos alunos surdos e que estes recorram à Libras como sua primeira língua e entendam a LP como sua L2.

Giselli Silva, professora da Faculdade de Letras da UFMG, lança, em novembro de 2018, um livro didático de português como segunda língua para crianças surdas. Segundo a professora, a ideia surgiu da demanda de professores por materiais que pudessem ser usados com as crianças para o ensino de L2. Esse material está disponível na página eletrônica da Faculdade de Letras da UFMG ${ }^{11}$.

Freitas (2018) defende dissertação com o título "A multimodalidade no ensino de Língua Portuguesa para alunos surdos nos anos iniciais: uma proposta de material didático" e propõe uma metodologia de ensino por meio de material didático elaborado pela própria, cujo texto base é um conto infantil e que considera três modos de significação: a imagem, a Libras e o português escrito. Quanto aos resultados, a autora manifesta que houve resposta positiva das professoras participantes, embora pondere ser determinante para o sucesso do ensino o desejo do aluno. Por fim, defende a necessidade de mais pesquisas na área e capacitação de professores para o ensino de LP como L2.

Com base na exposição dos pesquisadores, constata-se que LD e/ou MD bilíngues ou acessíveis em Libras são produtos elaborados por professores e a partir das demandas desses; como também, por pesquisadores ou editora especializados na área da surdez.

\section{Considerações Finais}

Retorno as indagações iniciais para afirmar: o LD adaptado em Libras de ensino de LP não se adequa como suporte para o ensino de segunda língua ${ }^{12}$. A tradução do texto escrito (LP) para o texto sinalizado (LS), isto é, as duas línguas (LS/LP) presentes no mesmo material, demonstra que a LS e a LP, podem estar simultaneamente envolvidas, associadas numa mesma tela em um formato digital. Entretanto, mantém o reforço de considerar a LS apenas como um suporte básico para o ensino da LP escrita.

Nos LD adaptados em Libras investigados nota-se que seguem um único padrão do desenvolvimento da linguagem, orientada pela língua majoritária, a língua oral do país. O LD pode apresentar padrões que regem as representações sociais - escrita/imagem/oralidade, pois acredita-se que esses paradigmas são parte da estrutura do conhecimento. Nessa configuração, a Libras representa uma língua que circula no LD; mas, não se caracteriza língua de ensino e aprendizagem.

Enfim, dentro desse horizonte educacional que trata do LD adaptado em Libras, tem-se, em Halliday (1998, p. 2), o argumento que todo processo educativo é mediado pela linguagem. A escola, acrescendo o LD, ocupa o lugar de ensino e aprendizagem constituído pelos diversos modos de linguagem, e esses modos devem estar compostos por concepções sobre o que os alunos devem e como aprender. Dentro dessa conjectura, pode-se elencar dois pressupostos: o principal, a crença que duas línguas circulantes já dizem de um material bilíngue, e, assim, acessível; e o segundo, que se trata

\footnotetext{
${ }^{10}$ Desenvolvido no programa Viver sem Limite, do governo federal, para o curso de licenciatura em Pedagogia Bilíngue, oferecido na modalidade on-line, visando à formação de pedagogos para atuar no ensino e na gestão escolar com enfoque na educação de surdos.

${ }^{11}$ Disponível em: http://www.letras.ufmg.br/portuguesl2surdos/. Acesso em: 20 jul. 2019.

${ }^{12}$ Língua Portuguesa
} 
da ausência de conhecimento e planejamento dentro das propostas que delineiam a educação bilíngue para crianças surdas.

Os recursos tecnológicos têm legitimado o uso da língua de sinais nos espaços educativos. Contudo, faz-se necessário repensar o uso desta ferramenta e sua adequação aos aspectos direcionados ao ensino de segunda língua, modalidade escrita. A entrada das tecnologias na educação das crianças surdas possibilita uma nova visão textual, isto é, concebe considerar não apenas simples adaptações tecnológicas, mas diferentes abordagens linguísticas e culturais.

Dessa forma, o processo de elaboração de materiais didáticos bilingues deve legitimar as diferentes unidades discursivas (imagem/LS/LP), que compõem as atividades pedagógicas, e, deve significar compreender novos códigos de leitura e escrita, novas linguagens e novas formas de interpretar o lugar na educação e o acesso ao ensino e aprendizagem.

O livro didático adaptado em Libras é uma realidade. Educadores que desconhecem o cenário sobre a surdez podem tomá-lo um produto de uso. Não há dúvida de que a tecnologia ocupará um lugar de destaque nas diferentes maneiras de conceber recursos didáticos para crianças surdas e se tornará, efetivamente, um elemento de uso real. Assim, acredita-se que crianças surdas e ouvintes expostas aos diferentes modelos linguísticos ganhem empatia pela semelhança e pela diferença. Entretanto, o modelo linguístico e cultural das pessoas surdas deve ser incorporado, bem como assegurar ambientes midiáticos culturalmente apropriados e que promovam interações na língua de sinais. O leitor surdo precisa encontrar sua identidade visual, precisa estar familiarizado com o material e experimentar sua interface, primeiramente, pela sua língua.

\section{REFERÊNCIAS}

BASSO, I.M.S. "Mídia e educação de surdos: transformações reais ou uma nova utopia?". Ponto de Vista, Florianópolis, no 5, 2003. p. 113-128.

BARBOSA, E.R.A; BARTHOLOMEU, I.C.S. "Ensino de Português como Segunda Língua: Análise dos Aspectos Gráfico-Editoriais de uma Unidade Didática Voltada a Alunos Surdos”. Revista Virtual de Cultura Surda, Petrópolis, nº 17, fev., 2016. p. 1-31.

BRASIL. Ministério da Educação. Parâmetros Curriculares Nacionais. Brasília, 3. ed., 2001.

COSCARELLI, C. V. "Leitura em ambiente multimídia e a produção de inferências". In: GUIMARÃES, Ângelo M. (ed.) VII SIMPÓSIO BRASILEIRO DE INFORMÁTICA NA EDUCAÇÃO, nov. 1996. Anais. Belo Horizonte: DCC/UFMG, p. 449-456.

FAVALLI, Paulo. Meus primeiros sinais. São Paulo: Panda Books, 2000.

FREIRE, F. M. F. “Surdez e tecnologia de informação e comunicação”. In: SILVA, I., KAUCHAKJE, S. E GESUELI, Z. (Org.) Cidadania, surdez e linguagem: desafios e realidades. São Paulo: Editora Plexus, 2003.

FREITAS, L. A. G. A multimodalidade no ensino de Lingua Portuguesa para alunos surdos nos anos iniciais: uma proposta de material didático. 2018. 146f. Dissertação (Mestrado em Estudos de Linguagens). Centro Federal de Educação Tecnológica de Minas Gerais (CEFET-MG), Belo Horizonte, 2018.

KRESS, G. "A Social Semiotic Theory of Multimodality". In: Multimodality: A Social Semiotic Approach to Contemporary Communication. USA e Canadá: Routledge, 2010. 
KRUSSER, R. S. Design editorial na tradução de português para Libras. 2017. 410f. Tese (Doutorado em Estudos da Tradução). UFSC. Florianópolis, 2017.

HALLIDAY, M. A. K. "The notion of context in language education”. In: GLADESSY, Mohsen. (Org). Text and context in functional linguistics. Amsterdam/Philadelphia: Unversidade de Brunei Darussalan. 1998.

LINS, H. A. M. "TDICs e os processos de alfabetização e letramento de crianças surdas e ouvintes: formação de professores". IX ENCONTRO VIRTUAL DE DOCUMENTAÇÃO EM SOFTWARE LIVRE E VI CONGRESSO INTERNACIONAL DE LINGUAGEM E TECNOLOGIA ONLINE. Anais. v. 1, no 1. 2012, p. 1- 11. Disponível em: http://evidosol.textolivre.org/ Acesso em: 5 jun. 2018.

MIRANDA, D. G. "As mediações linguísticas do intérprete de língua de sinais na sala de aula inclusiva". Dissertação de Mestrado. Faculdade de Educação. UFMG, Belo Horizonte, 2010.

MIRANDA, D. G. "A multimodalidade no ensino de lingua portuguesa como segunda língua para surdos: análise do uso do livro didático adaptado em Libras". Tese de Doutorado. Posling. CEFET-MG, Belo Horizonte, 2019.

MORAIS, F. E CRUZ; O. M. "Elaboração de material didático de Lingua Portuguesa como L2 para alunos surdos do curso de Pedagogia: Desafios e Possibilidades”. VI CLAFPL, Universidade Estadual de Londrina. 2016, p. 99-110.

MOSES, A. M., GOLOS, D. B.; HOLCOMB, L. "Creating and Using Educational Media with a Cultural Perspective of Deaf People”. In: Pectives on Practice. Language Arts, v. 96, n 1, set. 2018. p. 67-71.

MUNAKATA, K. "Livro didático como indício da cultura escolar". In: História da Educação (online), Porto Alegre, v. 20, nº 50 set./dez., 2016. p. 119-138.

NATIVIDADE, C.; PIMENTA, S. "A semiótica social e a multimodalidade". In: LIMA, C.H.P.; PIMENTA. S.M.O.; AZEVEDO, A.M.T. Incursões semióticas: teoria e práticas de gramatica sistêmicofuncional, multimodalidade, semiótica social e análise crítica do discurso. Rio de Janeiro: Editora Livre Expressão, 2009.

PIMENTA, S. "A Semiótica Social e a Semiótica do Discurso de Kress". In: MAGALHÃES, C. Reflexões sobre a análise crítica do discurso. Belo Horizonte: FALE/POSLIN/UFMG, 2001.

PREDIGER, A. e KERSCH, D. K. "Usos e desafios da multimodalidade no ensino de línguas". In: Signo. Santa Cruz do Sul, v. 38, n. 64, jan./jun. 2013. Disponível em: http://online.unisc.br/seer/index. php/signo. Acesso em: mai. 2017. p. 209-227.

QUEVEDO, S. R. P. Narrativas Hipermidiáticas para Ambiente Virtual de Aprendizagem Inclusivo. 2013. $379 f$. Tese (Doutorado em Engenharia e Gestão Do Conhecimento). Universidade Federal de Santa Catarina, Florianópolis, 2013.

RAMOS, C. "Livro didático digital em Libras: uma proposta de inclusão para estudantes surdos". In: Revista Virtual Cultura Surda, Petrópolis, Editora Arara Azul. 1ª ed. nº 11, jul. 2013.

SILVA, I. R; NOGUEIRA, A. S.; HILDEBRAND, H. R.; KUMADA, K. M. O. "Desenvolvimento de material didático para surdos: as relações entre imagem e escrita". In: XI CONGRESSO LUSO AFRO BRASILEIRO DE CIÊNCIAS SOCIAIS. Diversidades e (Des)igualdades. UFBA, Salvador, ago./2011, p. 1-13. 
SILVA, I. R; NOGUEIRA, A. S.; HILDEBRAND, H. R.; KUMADA, K. M. O. “O uso dos jogos eletrônicos no processo ensino-aprendizagem de surdos”. In: VALLE, L., MATTOS, M.J; COSTA (Org.) Educação Digital: a tecnologia a favor da inclusão. Porto Alegre: Penso, 2013, p. 213-238.

SOUZA, L. C. Recomendações para cursos on-line em Lingua Portuguesa com foco na integração de alunos surdos. 404f. 2015. Tese (Doutorado em Linguística Aplicada) Belo Horizonte, Universidade Federal de Minas Gerais, 2015.

STOCK, I; STROBEL, K. Brincando e aprendendo com Libras: língua brasileira de sinais. Universidade Tuiuti do Paraná, 1999, p. 1-72. 